\title{
Evolution of transformer health index in the form of mathematical equation
}

\begin{abstract}
Energy is a basic necessity in every country. The worldwide demand for energy will rise due to the developments of power generation in industrial, service, and residential sectors. A healthy power system is therefore very important to guarantee continuous electricity supply to the end users and this can be achieved through asset management. A proper asset management will allow asset managers to conduct quality assessment of conditions and to develop future management strategies of the electrical assets such as transformers. The execution of transformer asset management involves an investigation of the transformer's condition by employing Transformer's Health Index (THI). Mathematical equation/algorithm or expert judgment has been investigated by many previous studies as one of the technique to determine health index (HI). Some of the established methods of HI determination such as scoring and ranking method, tier method, matrices and multi-feature assessment model have led to the different interpretations of the final condition of a transformer. This paper critically examines and explores the previous studies related to transformer health index by using mathematical equation/algorithm or expert judgment. The concept of HI and its formulation are presented in this study. Generally, there are three parts of $\mathrm{HI}$ formulation which are input, algorithm for $\mathrm{HI}$ and the output of HI. The application of HI is discussed in terms of the performance of in-service transformer. The limitations of the available methods are also discussed and future works to overcome the problems are suggested.
\end{abstract}

Keyword: Transformer asset management; Transformer health index; Transformer condition monitoring; Renewable energy 